\title{
Development of Construction Technology of Customs Buildings in Canton in Modern Times
}

\author{
Ruirui Huang ${ }^{1}$, Qionglin liu ${ }^{2 *}$ \\ ${ }^{1}$ Ruirui Huang: Postgraduate, School of Art and Design, Guangdong University of Finance and Economics, No.21, \\ Luntou Road, Haizhu District, Guangzhou City, People's Republic of China. 510320 \\ ${ }^{2}$ Qionglin liu : Associate Professor, School of Art and Design, Guangdong University of Finance and Economics, \\ No.21, Luntou Road, Haizhu District, Guangzhou City, People's Republic of China. 510320 \\ *Qionglin liu.Email:L@gdufe.edu.cn

\begin{abstract}
The development of modern customs buildings in Guangdong accounts for an important part of the modernization of Chinese architecture. Due to the deep impacts of Western culture, the modern customs buildings in Canton reveal features of cultural exchanges between the West and China in the modern development. The churches in Canton boast a long history. This paper intends to probe into the building structure, equipment and green technology manifested in these churches through comparative analysis and the induction research method, with a vision to grasp the context and characteristics of the development of church buildings.
\end{abstract}

Keywords: Guangdong modern customs architecture, construction technology, building structure

\section{BACKGROUND RESEARCH}

Canton marks a unique chapter in the development history of modern cities and architecture in China. Deeply affected by the Western culture, the city and construction technology of Canton show traces of cultural exchanges between the West and China. Customs buildings are a unique category of the architectural culture.

Modern Canton customs buildings refer to buildings such as the Canton Custom House and Customs Club established by Western countries in Canton since the mid19th century. This article mainly analyzes the construction of Canton customs from the perspective of the construction structure, such as the brick (stone) and wood mixed structure, the brick (stone) steel-reinforced concrete mixed structure, and the brick (stone) reinforced concrete mixed structure. Integration of Chinese and Western architectural forms has a profound impact on modern Chinese customs architecture and plays a positive role in promoting the cultural development of the Guangdong-Hong Kong-Macao Greater Bay Area and the "Belt and Road".

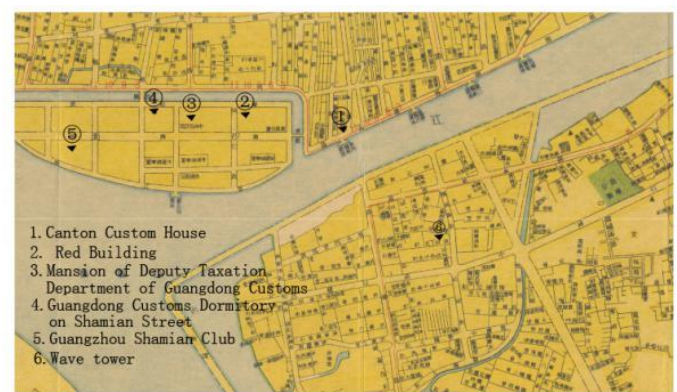

Figure 1 Distribution map of modern Canton customs buildings

Figure 1 shows the distribution of major customs buildings in Canton, including the Canton Custom House, Canton Customs Taxation Department Mansion, Canton Customs Club, Wave Tower distributed along the Pearl River and around Shamian Island. Due to the waterway, this region is ideally located and boasts convenience.

\section{DEVELOPMENT HISTORY}

This article attempts to probe into the customs buildings in Canton from the perspective of construction technology. To explore the construction technology of customs buildings in Canton, this study referred to the 
Lingnan architectural stage division method proposed by Prof. Peng. In "Development of Modern Canton Building Structuring Technology", Prof. Peng summarizes the development of modern structuring technology in Canton, the establishment of Lingnan Missionary School, and explores "the development and evolution of modern missionary school buildings in Canton". In that paper, Prof. Peng divides the emergence and development of modern customs buildings in Canton into the following three stages.

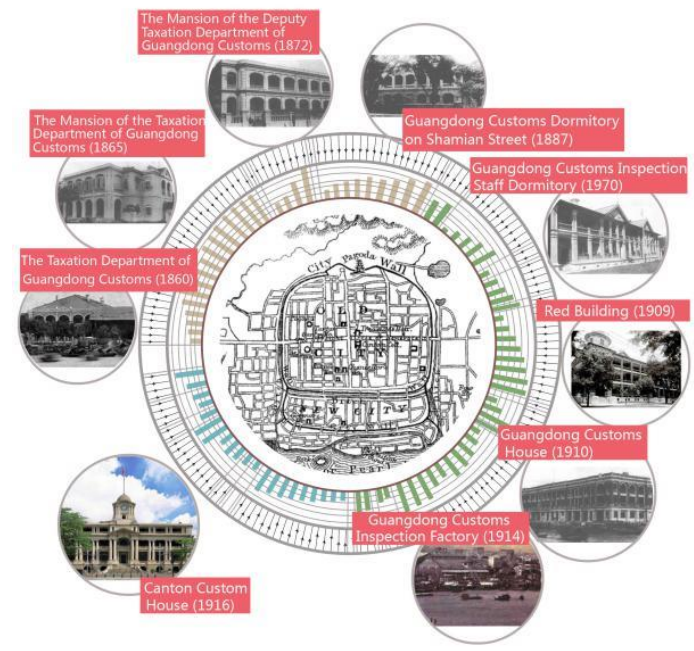

Early stage (1860--1887) Development period (1807-1914) Prosperous period (1916)

Figure 2 Modern Canton Customs Buildings Phase

\subsection{Early stage}

As stipulated in the "Treaty of Nanjing" signed by the Qing government in 1842, " five ports including Canton, Xiamen, Fuzhou, Ningbo, and Shanghai are opened as foreign trading ports where the British can live freely with their dependents and send consulates and other officials[1]". Since then, these five open trading ports including Canton opened the door for the West to China to build offices and living buildings.

In the mid- and late-19th century, the construction technology of western industrial countries underwent revolutionary changes. With the invasion of Western colonial powers and the introduction of new technology triggered by the Westernization Movement in the late Qing Dynasty in the 1860s and 1990s, new materials and construction structures like Portland cement and steel emerged in China, leading modern Chinese architectural technology towards modernization[2].

The intensive contact with foreigners in Canton after the first Opium War allowed the people in this city to have a better understanding of foreign technology and culture. As the Qing Dynasty failed in the Opium War and previous wars against aggression, Canton was forced open to the outside world and China was transformed into a semi-colonial and semi-feudal society. This situation, however, also has some benefits, as people are gradually awakened to the superiority of advanced culture and technologies introduced from the West. As the government tried to save China from aggression by introducing Western civilization, the architecture culture and technologies were put on the track of modernization.

Most buildings in this period adopted the brick (stone) and wood mixed structure. These buildings generally have two-story sloping roofs or flat roofs, and the building facade is a two-story brick voucher gallery[3] The building structure is disproportionate and details require improvement. The outer walls are made of blue bricks with red brick horizontal lines, such as the Dormitory of Canton Custom House on Shamian Street. The outer surface of the wall is not painted. Ding's British masonry and voucher arch masonry are typical examples of the introduction of this technology and structure.

\subsection{Development period}

At the end of the 19th century and the beginning of the 20th century, the technology colonization system represented by Shamian and the technology introduction system represented by Westernization Construction pushed the introduction and application of new materials and new structures to a climax. The emergence of new materials and new structural technologies has forced the establishment of a new modernized material and structural system. Its specific manifestations include: cement and steel are introduced to the brick (stone) and wood mixed structure to improve technical performance, which leads to the bricked (Stone) wood-steel hybrid structure and brick (stone) steel-reinforced concrete hybrid structure. The Canton Customs Club, the Customs Administration Office and the Dormitory of the Canton Custom House on Shamian Fifth Street are representative buildings of this period.

Most buildings in this period adopted the brick (stone) steel-reinforced concrete mixed structures, and new construction facilities like electric lighting, water supply and drainage, and air conditioning appeared inside the buildings. The green construction technology also came into play. In addition to changes in the structure and height, there is a trend of combining local materials and technologies in construction, such as using ventilation and heat dissipation dormer windows and wooden shutter doors with characteristics of Central China in the buildings.

\subsection{Prosperity period}

After the short-term adoption of steel-reinforced concrete technology, the structure of Lingnan's modern buildings transitioned to a more reasonable reinforced concrete structure. In 1824, Britain first produced colloidal Portland cement, which laid a foundation for 
development of concrete structures[4]. In 1905, the Martin Hall of Sun Yat-sen University was the first reinforced concrete mixed structure in modern China, and Canton customs buildings later adopted this structure[5]. The development of buildings is inseparable from the solution to vertical traffic problems. The invention of the safe passenger lift by Otis in the United States in 1853 made the construction high-rise buildings possible. On the whole, modern Lingnan and even across China have basically kept up with the advanced countries in the construction techniques. In other words, the construction technology of modern customs buildings in Lingnan has developed in line with the trend of the world.

In this period, the buildings adopted the "Kang"-type reinforced concrete structure. In terms of building facilities, elevators and mechanical transmission-type vertical clocks were installed inside the buildings; in terms of the green construction technology, the method of semi-basement elevated floor was adopted to adapt to the rainy and humid climate of Lingnan, with the air vent reserved, and the horizontal ventilation hole pallet installed on the roof[6], Ventilation is arranged at the "waist door" outside the room, which blocks the sight and constitutes a good ventilation system inside the building. There are as many as 23 shallow hearth fireplaces burning charcoal inside the building, forming a good moistureproof heating system.

\section{CHARACTERISTICS OF THE DEVELOPMENT OF CONSTRUCTION TECHNOLOGIES OF MODERN CUSTOMS BUILDINGS}

As an important force to promote the continuous development of architecture, the structural technology is the material basis and prerequisite for the modern transformation of Chinese architecture.

\subsection{Building structure}

The structural technology is an important force to promote the continuous development of architecture.

In the initial stage, the customs buildings in Canton include Taxation Department Office of Canton Custom House, the Mansion of the Taxation Department of Canton Custom House, the Mansion of the Deputy Taxation Department Office of Canton Custom House , and the dormitory of Canton Custom House in Shamian Street. Most of the buildings adopt the brick (stone) wood mixed structure, which is usually characterized by the combination of brick (stone) bearing walls, wooden staircases, voucher arches and beam wood floors. In addition, the wooden beam slab floor is another important feature of this period, such as the Mansion of Taxation Department of Canton Custom House . The structure consists of a beam slab with the wooden main beam and the multi-ribbed wood beam supporting the wooden floor together, which represents the technical characteristics of the quantitative stress analysis of Western architecture.

During the development period, the customs buildings include the Canton Customs Inspection Staff Dormitory, the Customs Red Building, Canton Customs Wave Building and Canton Customs Inspection Factory. The buildings in this period mainly adopt the brick wood steel frame mixed structure and steel reinforced concrete structure, which are usually the brick (stone) steel reinforced concrete mixed structure, that is, a structure featured by thick bricks and stone bearing walls. The floor structure is arranged parallel to the section steel to form multi ribs, and the spacing of multi ribs reaches about $1.5 \mathrm{~m}$. Compared with the initial stage, I-shaped steel structure appeared in this period. For example, Canton Customs Club (the Red Building) was based on red bricks and I-shaped steel, with brick walls inside and arches outside.

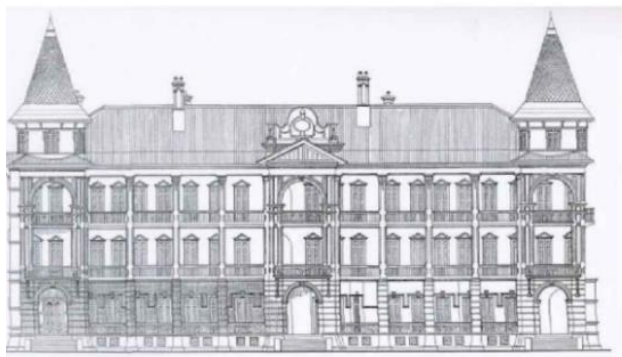

Figure 3 elevation of Red Building[7]

During the prosperous period, there was the Guangdong Customs Administration Office. The building adopts the "Kang"-style reinforced concrete structure (Fig.4 and 5). The technical basis of the structure was the "Kahn bundled bar" invented by American Julius Kahn, that is, the steel bar system composed of a horizontal main bar with mounting flange and a composite steel bar with rigid connection by $45^{\circ}$ diagonal.

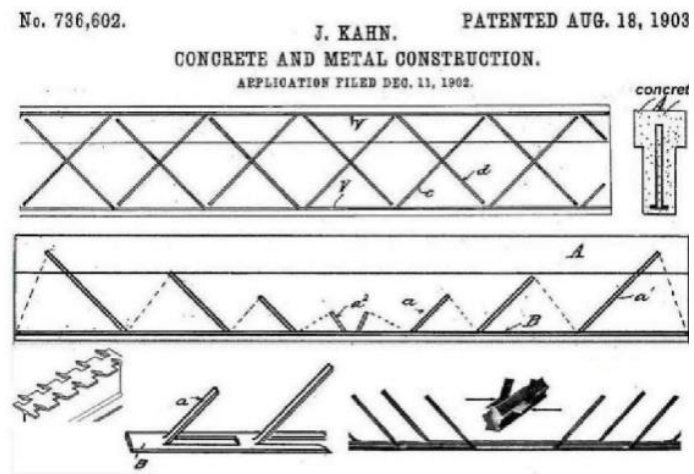

Figure 4 Diagram 1 of the "Kang"-style steel concrete structure 


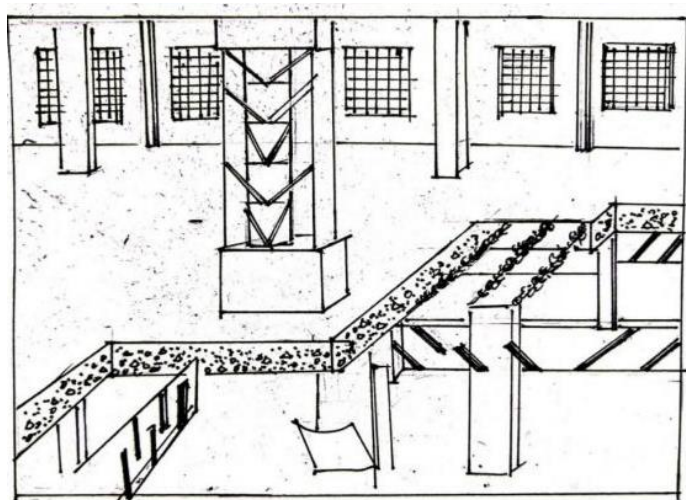

Churches are another form of architecture rising in the modern times in China. The construction features of churches and the customs buildings are compared in this paper.

Figure 5 Diagram 2 of the "Kang"-style steel concrete structure

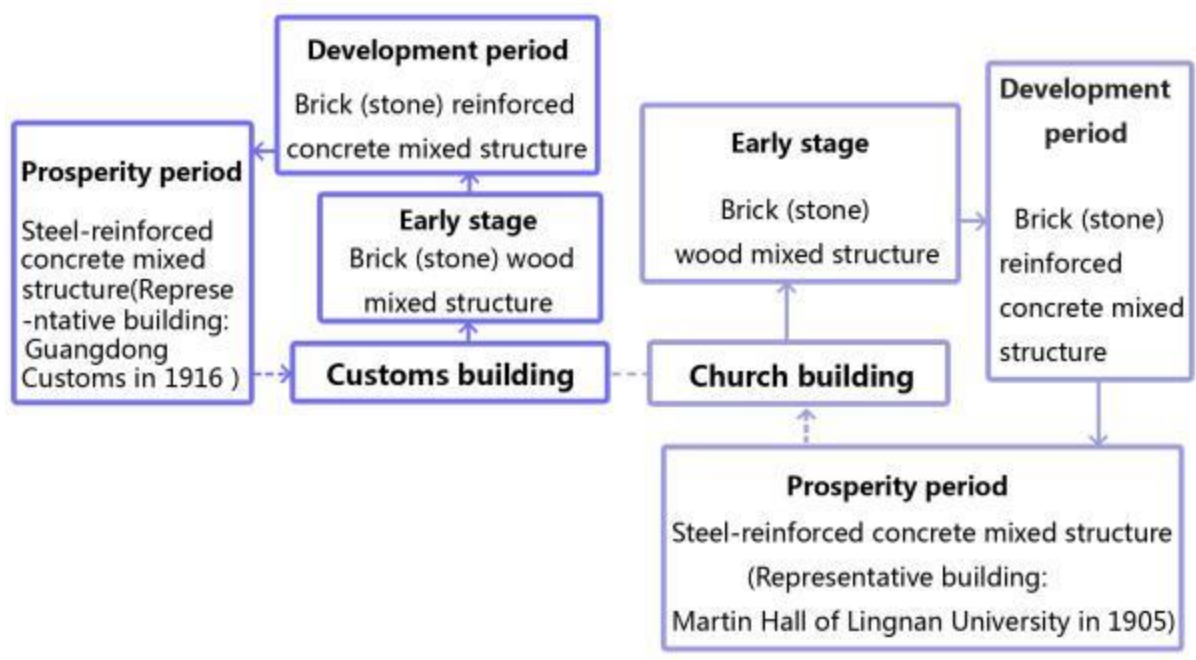

Figure 6 Comparison of customs buildings and church buildings

Comparison of customs buildings and churches reveal that the use of reinforced concrete in the Martin Hall in 1905 marks the basic synchronization of modern Lingnan and even China with advanced countries in construction techniques. After the Martin Hall, the new reinforced concrete structure is used in Guangdong Customs Administration Office, which keeps abreast of the development of Western Europe.

\subsection{Construction facilities}

With the development of construction technology and materials, new construction facilities come into being. New facilities and technologies such as electric lighting, water supply and drainage, air conditioning appeared in China in the late 19th century and early 20th century. These new facilities developed in full swing due to the increasing complexity of buildings, and kept in line with the development of building structure and building material technology.

In the initial period, the building facilities of the customs buildings are relatively simple. They are generally two-story buildings, with many protruding chimneys on the roof, fireplaces, wooden stairs and other facilities inside. Typical examples include the Dormitory of Canton Custom House in Shamian Street and the Taxation Department of Canton Custom House .

With the development of building materials and construction technology, the customs building facilities in the development period are gradually enriched. For example, the black cast iron drainage pipe appears in the Red Building of the Customs Administration, the steel pool is set on the roof of the building to store water, and the cast iron water supply pipe is introduced into each water room and toilet, and the water is discharged into the sand drainage system. The roof of the building is drained by dint of the natural slope, the cast iron open drain channel around the roof is used to collect water, and the rainwater is discharged to the ground or sewer through the exposed cast iron downpipe [8]. As Figures 7 show, inner chandeliers are hung inside the Red Building and along the corridor, which speaks to the perfectness of the power system. Compared with the start-up period, this period saw the enriched forms of construction facilities, with the rise of new construction systems like drainage systems and power systems. 


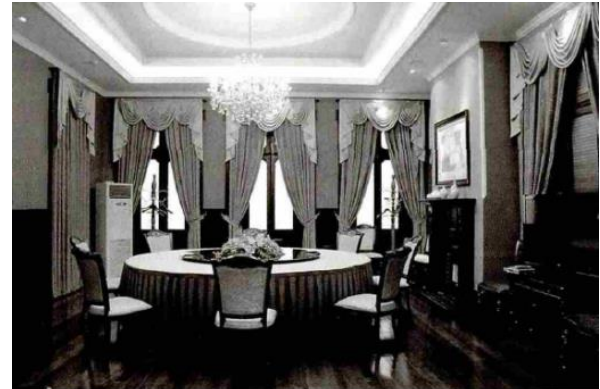

Figure 7 Red Building interior[8]

The customs buildings in the prosperous period are $\mathrm{r}$ epresented by the Canton Customs Administration Office. The use of elevators, the improvement of drainage systems and fully mechanically driven Vertical clocks are important signs of this period. The elevators have been put into use in American buildings since 1887, and in 1889, The Eiffel Tower began to use elevators[4]. At the beginning of the 20th century, elevators appeared in Canton. They first appeared in the Shamian Ruiji Foreign Company in 1905 for indoor vertical transportation, and later in the Canton Custom House. In terms of the drainage system, the drainage system was rebuilt in Shamian Island in 1904. In 1907, the Canton Xiguan Water Tower was built on Changshou Street. In June 1908, the Zengcheng Water Plant was completed, and water was officially supplied in August[5]. A black cast iron water collection pipe appeared on the north facade of the Canton Custom House (Figure 8) and it can be inferred from the time record that the drainage system of Canton Custom House in 1916 was relatively complete. Fireplaces are arranged in the buildings of Canton Custom House for heating, ventilation, and moistureproof purposes. For the first time, a fully mechanically driven vertical clock (Figure 9) is used. The large internal device is a 1915
British original vertical clock, which is a complete mechanical transmission type vertical clock currently rare in China[9]. In this period, elevators, complete drainage systems and fully mechanically driven vertical clocks appeared.

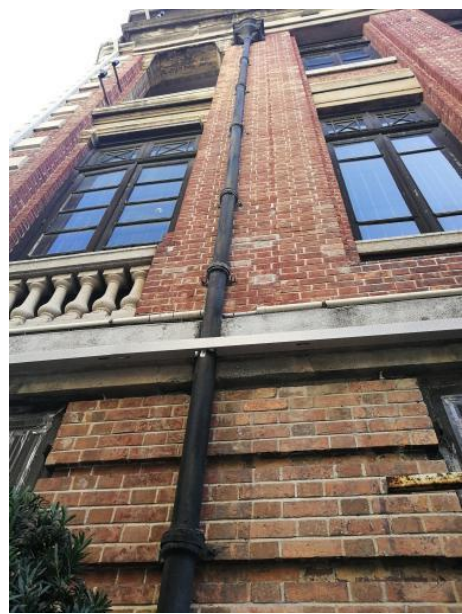

Figure 8 The back (north) elevation of the Canton Custom House

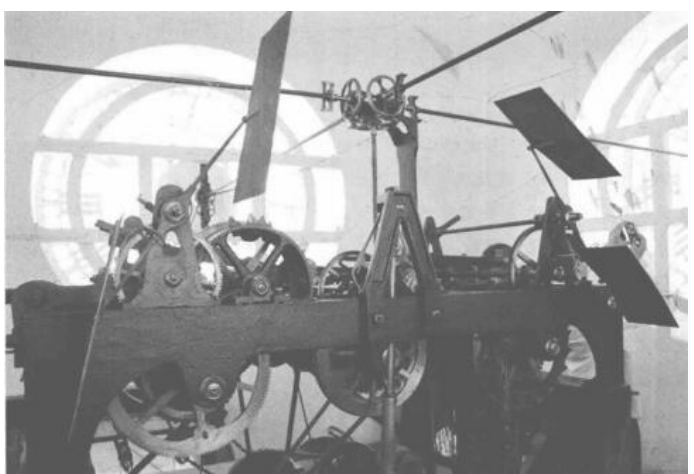

Figure 9 A recent photo of the movement of the clock in Canton Custom House[9]

The development is manifested in the Canton Missionary School (Figure 10).

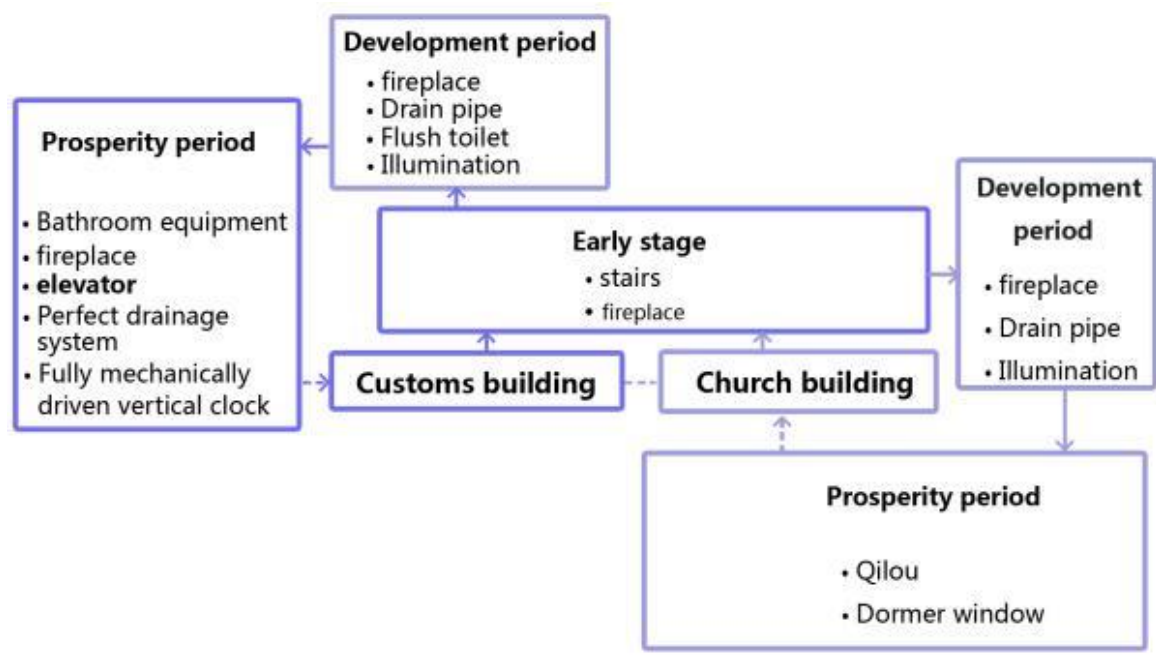

Figure 10 Analysis of construction facilities 
Analysis of the construction facilities of customs buildings and church buildings in the three periods shows that the customs buildings and church buildings in the start-up stage present the same development trends as in the development period.In the prosperity period, however, the watershed is the major difference between the customs building and the church building.Elevators and fully mechanically driven vertical clocks appeared 20 years in customs buildings earlier than in church buildings, and they also have a leading position in modern Lingnan architecture.

\subsection{Green technology}

Canton has a subtropical monsoon climate with the characteristics of long summers, abundant rainfall, high humidity and much rain. Westerners often find it hard to adapt to the climate there. To address the problem of excessive heat and humidity, the Western designers of the customs building in the initial stage adopt the building styles in colonial areas with similar climates to Canton, such as Southeast Asia or Hong Kong and Macau, emphasizing ventilation, moisture-proof performance and thermal insulation of the buildings. The Taxation Department of Canton Custom House (Figure 11) is a typical example. The building is a twostory four-sloping roof building. As Figure 11 shows, there are five smoke outlets on the roof, and the building has adopted fireplace insulation technology. In terms of ventilation, on the Mansion of Taxation Department of Canton Custom House (Figure 12), the roof was no longer a flat roof, but equipped with horizontal vents. Different forms of external window ventilation design appeared, and the ventilation system was perfect.

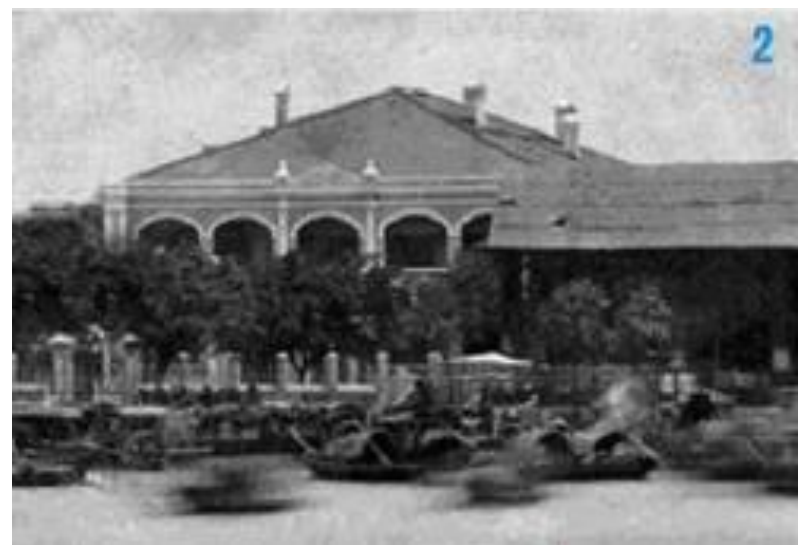

Figure 11 Taxation Department of Canton Custom House [10]

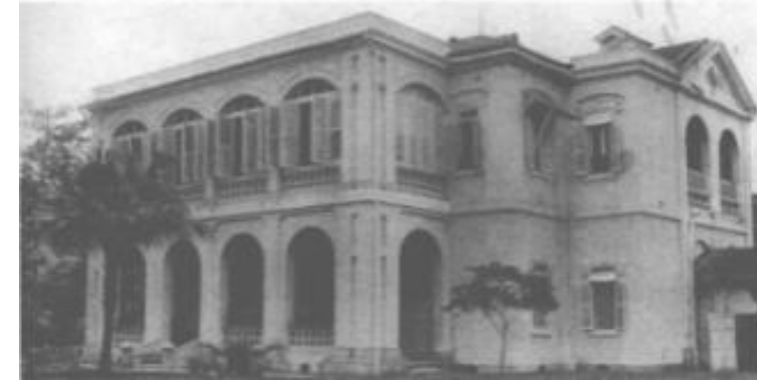

Figure 12 Mansion of Taxation Department of Canton Custom House[9]

Green construction technology adopted in customs buildings in the development period usually use green materials to achieve good ventilation, heat preservation and moisture prevention in light of the local environment. At the bottom of the building, a half-story stone base is raised, serving as a cellar. This method of raising the first floor not only retains the traditional characteristics of European-style buildings, but also suits the rainy and humid climate in Canton. During this period, the depth of the building increased, the rooms were separated, the wind was difficult to pass through, and the ventilation performance was poor. Therefore, we made improvements based on the local environment of Lingnan: the outer corridor was retained, the inner corridor was added, and a skylight was opened on the top of the inner corridor (Figure 13). For example, the Dormitory Building of Canton Custom House on the Fifth Street of Shamian uses dormitory windows for ventilation and heat dissipation, which is characteristic of buildings in Central China. In the Red Building (Figure 14), the roof of the building has a natural slope for drainage, a cast iron open channel surrounding the roof collects water, and the rainwater is drained to the ground or sewer through the exposed cast iron downpipe. In terms of heating, the heating system in the Red Building consists of a wooden mantel, a real fire fireplace and a chimney protruding from the roof. The hearth is a cast iron fireplace core installed in the middle of the partition wall, and combined with the indoor wooden floor, building facade insulation structure wall and double exterior doors and windows, so as to achieve the heating effect of the entire building; in terms of green building materials, the roof of the Red Building uses roof alloy corrugated tiles which are mainly made of zinc, tin, aluminum and other metals. It has been used for many years and has not rusted, rotted or leaked. Previous studies show that this material was used as a temporary material for military construction during the First World War. It is light and beautiful without rusting. Compared with in the start-up period, the green technology of buildings in this period showed the practice of overhead half-story stone bases, the use of ventilation and heat dissipation dormer windows that are characteristic of Central China, and the use of green building materials. 


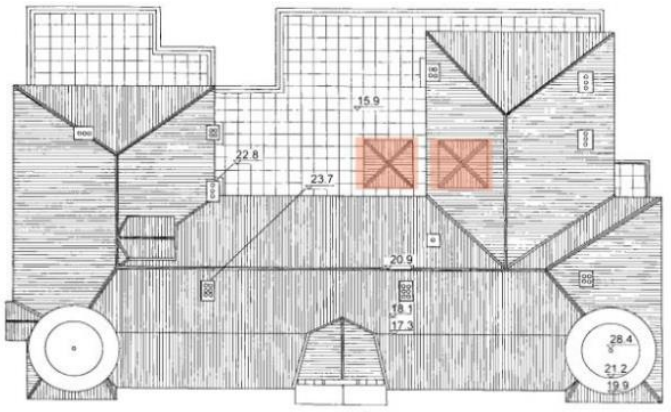

Figure 13 ventilation and lighting shaft[7]

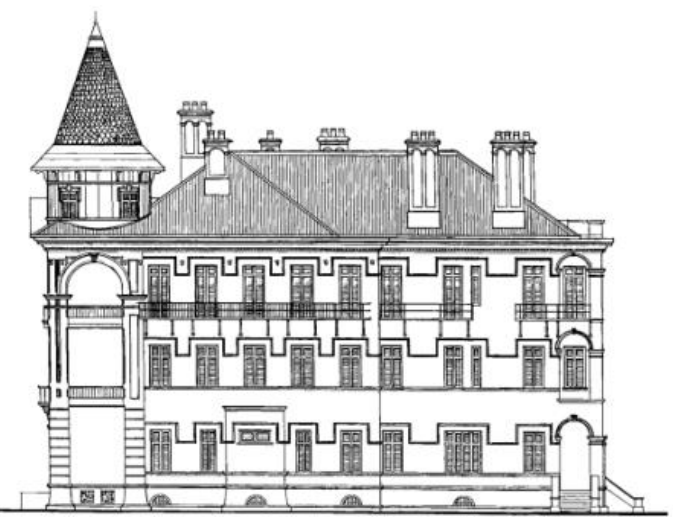

Figure 14 East elevation of Red Building[7]

In terms of ventilation and damp-proof performance, the buildings in the prosperous period continued the practice of the early half basement elevated floor, and removed the exhaust outlet, increased the floor height, and set the horizontal ventilation hole pallet on the roof. Besides, a "waist door" (Figure 15) with ventilation and line of sight barrier is installed outside the door of the room to generate a good ventilation system for the building. In case of damages by ants and fire, noncombustible materials such as cement, stone, reinforced concrete and brick strip-shaped hollowed-out decorations are used on the ceiling of each floor in the building to facilitate ventilation. Some of the external walls with stuffy roofs also have small square holes to improve ventilation . Compared with the development period, this period uses more new green construction technologies: the "waist door" and non-combustible materials are used to improve ventilation, moisture-proof performance and achieve the line of sight barrier by using semi-basement overhead floor(Figure 16).

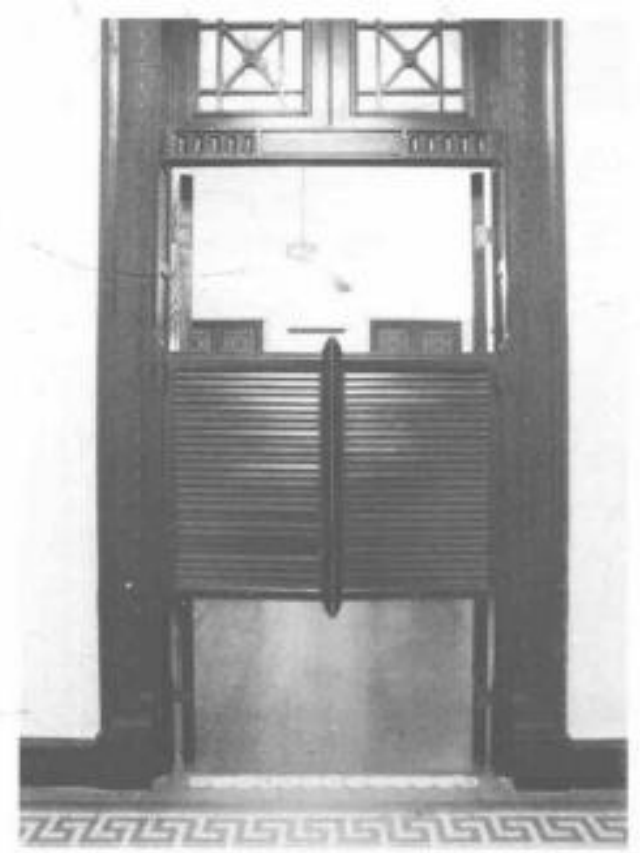

Figure 15 Waist door[9]

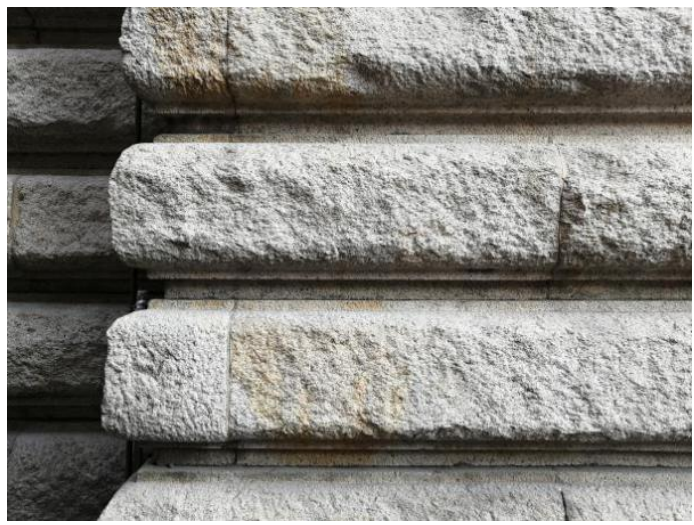

Figure 16 Cement material

Analysis of Canton Missionary School reveal the features of green technology in different stages. 


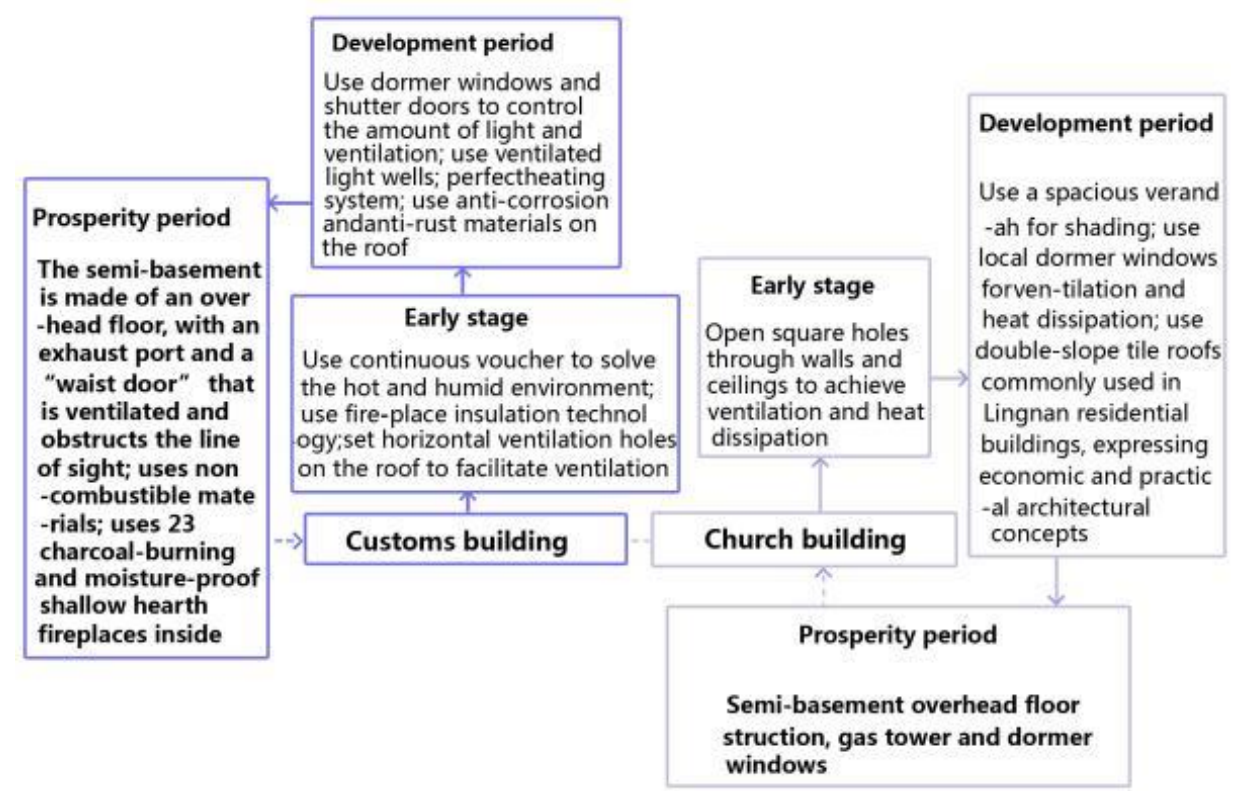

Figure 17 Analysis diagram of adoption of green technology in customs buildings and church buildings

Analysis of the building green technology adopted by customs building and church building in these three periods shows that the form of green technology in customs buildings and church buildings is gradually enriched and fitted to the local environment of Lingnan, but the customs buildings pay more attention to the use of green technology in construction.

\section{CONCLUSION}

The development of customs buildings in Canton has promoted the modernization of Lingnan architecture to a certain extent. For a long time, it was plundered by the West. Its architectural structure, facilities and green technology were completed by western architects, which played an important role in the exchange of architectural culture between China and the West. This study compares the modern customs buildings and church buildings in Canton in terms of the structure, facilities and the green construction technology. It is found that the new reinforced concrete structure is adopted both by Canton customs buildings and the Martin Hall, which follows the development of Western Europe; the modern customs buildings and church buildings develop synchronously in terms of adoption of green technology; however, in the aspect of architectural design, there are many problems, and the modern customs building is nearly 20 years ahead of the church building, which has a leading position in Lingnan modern architecture.

The development of construction technology of modern customs buildings in Canton have the following characteristics:

(1) The transformation period of structural technology is short, and the application of new technology in China is basically synchronized with the world. From the large-scale introduction of the
Western brick wood mixed structure to the completion of the Canton Custom House in 1916, Guangdong modern customs buildings

completed the introduction of a series of new materials and new technologies in less than 100 years. Its technology conversion cycle is short and its popularization is fast. The emergence of some new technologies, especially the reinforced concrete structure technology, in Guangdong modern customs buildings is basically synchronized with the world, which makes Guangdong modern customs buildings one of the important sources of modern new technology dissemination in Chi na.

(2) Guangdong customs buildings play an important role in the exchange of architectural culture between China and the West. In addition, Guangdong customs buildings not only integrate the architectural forms in China and the West, but also learn from Lingnan local architectural features, such as roof, frame, ventilation and moisture-proof systems, which is a beneficial exploration of the local architectural culture style.

\section{REFERENCES}

[1] Cheng H. The History of Ports in Guangzhou (Modern Times) [M]. Beijing: China Ocean Press, 1985.

[2] Peng C. X. Introduction to development of modern architectural structural technology in Canton [J]. Building Science, 2008(03):144-149.

[3] Wang T. Zhang F. H. Proceedings of the $5^{\text {th }}$ Seminar on the history of Chinese modern architecture [M]. China Architecture \& Building Press. 1998. 
[4] Tongji University. History of foreign architecture in modern times[M]. China Architecture \& Building Press. 1982.

[5] Peng C. X. Modernity and locality - modern transformation of Lingnan cities and architecture [M]. Tongji University Press. 2012-03.

[6] Fu J. Cai Y. Y. Liu Q. L. Research on the development of Chinese modern customs buildings based on analysis of Canton customs buildings [J]. Traditional Chinese Architecture and Gardens.03(2014):66-73. DOI:CNKI:SUN:GJYL.0.2014-03-026.

[7] Tang G. H. Modern building clusters in Shamian, Canton - Art, Technology and Protection [M]. Canton: South China University of Technology Press. 2004 (08): 1.

[8] Liu Q. L. Cheng J. J. Interpreting the value of Red Mansion (the former Canton Customs Club) in Shamian of Guangzhou based on Burra Charter [J]. Architectural Journal, 2013(S1):76-84.DOI : 10.3969/j.issn.1000-0232.2015.04.115

[9] Illustrations of customs buildings in modern times in China [M]. China Customs Museum, China Customs Press. 2017.

[10] Liu Q. L. Research on modern commercial and trading buildings in Canton [D]. South China University of Technology. 2015. 